\title{
The Impact of Tourism Product Harm Crisis Attribute on Travel Intention
}

\author{
Yue Li ${ }^{1, a^{*}}$, Dongli Tang ${ }^{1, b}$, Ting Tao ${ }^{1, c}$, Nanxiu Guo ${ }^{1, d}$, \\ Sha $\mathrm{Li}^{1, \mathrm{e}}$, Ziming Zhang ${ }^{1, f}$ and Xue Yang ${ }^{1, g}$ \\ ${ }^{1}$ Tourism School, Sichuan Agricultural University, Dujiangyan, China \\ a26005476@qq.com, b280906410@qq.com, c 1601647005@qq.com, d1582727141@qq.com, \\ e 554206464@qq.com, ${ }^{\dagger} 514061552 @ q q . c o m,{ }^{9} 763462116 @ q q . c o m$ \\ * The corresponding author
}

Keywords: Tourism Product; Travel Intention; Product Harm Crisis Attribute

\begin{abstract}
In recent years, with a number of tourism product harm crisis, such as the Black Tour Guides, the tigers which injured people in the zoo happened frequently, tourism product harm crises attract tourists' attention increasingly. However, it can be seen that there is a lack of researches on tourism product harm crisis attribute. By combing the literature, the paper concludes that tourism product harm crisis involves risk, severity, legitimacy and controllability. This paper will study the influence of four attributes on travel intention. Through questionnaire surveys, it was concluded that the risk and legitimacy have a significant negative impact on travel intention. Controllability has a significant positive impact on travel intention. Severity has no significant impact on travel intention.
\end{abstract}

\section{Introduction}

In recent years, tourism product harm crisis events have occurred frequently in China, such as the tiger in Badaling Zoo which injured people incident in July 2016, and the robbery of Chinese tourists in Thailand in March 2017, etc. Crisis events threaten tourists and property safety, lead tourists to change their travel decisions and destroy the destination image. For the government and enterprises of the tourist destinations which have occurred crisis, understanding tourism product harm crisis attribute is essential to target solutions.

By searching database, the existing research mainly focuses on product harm crisis attributes, product harm crisis spillover effect and corporate response. However, it's found that there's limited researches focusing on tourism product harm crisis and tourism product harm crisis attribute. Crisis attribute is the main characteristic of crisis events. Nevertheless, this may lead to tourists' perception of tourism product harm crisis attributes be different from other industries. Therefore, the purpose of this paper is to study the influence of tourism product harm crisis attributes on travel intention, enrich the research content of product harm crises.

\section{Literature Review and Research Hypothesis}

Tourism Product Harm Crisis Attribute. Product harm crisis event refers to the event which occasionally appears and is widely publicized about the defect of a product or the danger to consumers[1]. Scholars mainly study product harm crisis attribute, the impact of product harm crisis on consumer behaviors, product harm crisis spillover impact and product harm crisis response strategy.

Product harm crisis attributes are the chief characteristics of product harm crisis events. At present, scholars have pointed out that product harm crisis has severity[2,3], risk[3], justifiability[4], controllability[2], law violation[5], accountability[2,6] and frequency[7] etc.

At present, limited researches have clearly proposed the definition of tourism product harm crisis. Therefore, combining product harm crisis (refers to the incident which occasionally appears, is widely publicized and about a product that is defective or dangerous to consumers[1]) and tourism crisis (refers to the unexpected event which affects tourists' confidence in tourism and normal operation of tourism activities(WTO,2003), tourism product harm crisis is defined an event that 
occasionally appears, is widely publicized and affects tourists' confidence in tourism and normal operation of tourism activities. Combining with product harm crisis attribute, this paper puts forward four attributes of tourism product harm crisis event: severity, risk, legitimacy and controllability. This paper will study the influence of those four attributes on travel intention.

The Relationship between Risk and Travel Intention. Safety and security concept is the principal determinant of travelers' decision to visit a place[8]. Scholars generally agree that tourists concern about the security risks of tourist destinations after the tourism crisis[9]. Rittichainuwat and others[9] have found that security concerns had led to the loss of large numbers of tourists. As a result, when tourism product harm crisis occurs, customers will primarily consider safety issues, that is, the perception of risk.

Risk is used to measure the degree of danger which associated with consumer-related defective tourism products[1]. It's found that tourists make travel decisions based on perception rather than reality. Risk perception, rather than facts or actual hazard, affects the behavior of tourists to avoid or cancel trips to specific destinations[10]. The behavior of tourists and the image of tourist destinations are significantly affected by tourists' perception of risk[11]. When customers feel too dangerous, they change their plans or behaviors, such as canceling travel plans or evacuating from perceived dangerous destinations[12].

In general, the more serious the product harm crisis is, the higher the perceived risk of consumers and the greater the negative impact is[13]. Empirical research shows that customer's perception of risk is negatively correlated with their purchase intention after product harm crisis[14]. Ke Jiang found that risk perception negatively affected expected satisfaction and travel intention[15]. So tourists' perceived risk will affect travel intention. We hypothesis:

H1: The risk of tourism product harm crisis has a significant negative impact on travel intention.

The Relationship between Severity and Travel Intention. Ming Tu, Fengjie Jing and Xingdong Wang believe that the generation of purchase intention is the result of costumer threat assessment[16]. In the theory of protective motivation, threat assessment consists of perceived severity, perceived vulnerability and perceived benefits. Severity refers to the seriousness of the negative consequences of the threat.

Risk perception is often used to predict behavioral intention in marketing research. After the product crisis, customer purchase intention will be negatively affected by risk perception[16]. The serious tourism product harm crisis will not only destroy the brand image of the tourist destination, but also affect the consumer purchase intention[17]. From the perspective of the tourism industry, the occurrence of serious tourism product harm crisis will affect tourists' travel intention. With the spread of information on the significant decrease about the number of tourists in the affected scenic spots, tourists may give up travelling to the disaster areas after the severe natural disaster crises, as a result, the phenomenon of conformity is produced, which reduces travel intention[3]. This is the basis of the following hypothesis:

$\mathrm{H} 2$ : The severity of tourism product harm crisis has a significant negative impact on travel intention.

The Relationship between Legitimacy and Travel Intention. The issue of legitimacy has received significant attention in both the political and organizational sciences[18]. In the field of organizational science, Suchman argues that legitimacy refers to the norms, values, beliefs and interpretation systems in which an entity's actions are constructed in some societies, which are desirable and appropriate, as reflected in the recognition of the organization by the stakeholders or bystanders of the organization[19]. On the basis of Smith and Larry's research, Zheng Fang used the violation of law as a classification criterion for product harm crisis. It can be divided into two types: the justifiability and the non- justifiability [4]. In this paper, the relationship between legitimacy and travel intention will be studied from the perspective of social identification and law.

Reviewing previous studies founds that the organization with legitimacy has greater credibility and reliability, and is easier to obtain customer and other stakeholders' recognition and support[20]. In addition, corporate compliance with laws and regulations and social morality has become an 
important part of corporate social responsibility. Corporate social responsibility behavior affects customer purchase decisions. The higher the perceived social responsibility of the company, the more willing consumers are to support the company by purchasing its products [21]. This is the basis of the following hypothesis:

$\mathrm{H} 3$ :The legitimacy of tourism product harm crisis has a significant positive impact on travel intention.

The Relationship between Controllability and Travel Intention. Xingdong Wang, Fengjie Jing and Ming Tu found the attribution of tourists causes negative comments[22].Based upon attribution theory, we propose that tourism product harm crisis is controllable. Controllability means if is it possible to avoid the occurrence of a crisis event[23]. Previous research found controllability not only affects customers' perception of service quality, but also affects customer satisfaction, customer purchase behavior and customer loyalty[24,25]. Customers think service providers haven't controlled the situation effectively when a crisis event is caused by other customers[26]. The more customers think the occurrence of injury is in control of the service provider, the lower the overall satisfaction evaluation and the repatronage will be[27].This is the basis of the following hypothesis:

H4: Controllability has a significant negative impact on travel intention.

Hypothetical Model. This paper proposes a hypothetical model for the risk, seriousness, legitimacy and controllability of tourism product harm crisis. Figure 1 provides the hypothetical model.

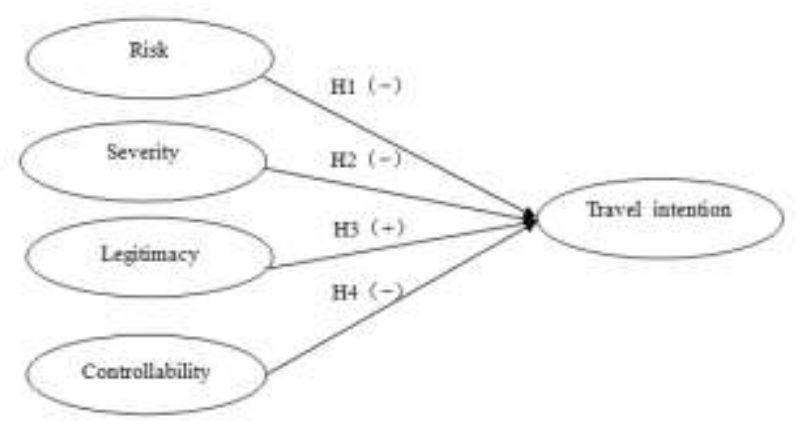

Figure 1. Finite Hypothetical model

\section{Research Design}

This study collects data through questionnaires. The background material of questionnaires is the tiger injury incident in the Badaling Wild Animal Park. In order to avoid respondents being disturbed, this paper objectively states information about the zoo and the zoo's name is anonymous.

Based on the characteristics of tourism products, the final scale of this paper is formed after discussion with a professor.

Risk was measured using seven items from Dawar \& Pillutla (2000) and Simokos \& Kurzbard(1994) risk scale. Severity was measured using seven items from Xingdong Wang, Fengjie Jing and Ming Tu (2014) severity scale. Legitimacy was measured using seven items from Certo

(2007) legitimacy scale. Controllability was measured using seven items from $\mathrm{Yu} \mathrm{Lu}(2012)$ controllability scale. Travel intention was measured using seven items from Sparks \& Pan （2009） travel intention scale.

Pretest Questionnaire. The Cronbach' $\alpha$ is 0.735 . The Cronbach' $\alpha$ is significantly higher after the deletion of item 13 or 11 . Therefore, item 13 and item 11 is deleted and the Cronbach' $\alpha$ is 0.814 , and the Cronbach' $\alpha$ does not increase obviously after the deletion of any item, indicating that the overall reliability of the scale is good. After exploratory deletion of item 11 and 13, exploratory factor analysis was carried out. The combined variance of four factors was $75.310 \%$. It shows that the scale of deleted items 11 and 13 has good construct validity.

Formal investigation. The formal questionnaire was conducted online in May 2018. The survey 
repondents were mainly in 18-25 years in Sichuan. The survey was collected by random sampling, and 280 questionnaires were collected. After screening, remaining effective questionnaires is 255 . The applicable recovery rate of the questionnaire is $91.8 \%$.

\section{Data Analysis}

Basic demographic characteristics. In the total sample, 33\% were males and $67 \%$ were females. $70 \%$ of respondents are under 25 years of age, $30 \%$ of respondents over 26 years of age. $22 \%$ of the respondents have a degree below junior high school, $59 \%$ have bachelor degree, $19 \%$ have master degree or above.

Reliability Analysis. The paper uses SPSS 23.0 to test the internal consistency of data. The Cronbach' $\alpha$ over 0.6 is considered to be accepted. The Cronbach' $\alpha$ of each variable is between $0.62-0.936$, indicating that the reliability of the scale is good.

Validity Analysis. AMOS 22.0 was used to conduct confirmatory factor analysis (CFA). The model fitting is successful. The results are as follows, factor load $\lambda>0.5, p<0.001$, representing potential variables have strong explanatory power for measurement variables, and five latent variables are meaningful for interpreting variables. Combined reliability $>0.63$, indicating that the internal consistency of the scale is good and the reliability is good, the average variance extraction (AVE) of risk, severity, legitimacy and tourism intention $\geq 0.5$, indicating that the intrinsic quality of the model is good, and each dimension has good convergent validity. The average variance extraction of controllability is 0.369 . Fornell \& Larcker thinks that the average variance extraction between $0.36-0.5$ is acceptable [28].

Confirmatory factor analysis was used to compare the four-factor model, the three-factor model and the single factor model. The four-factor model fits the actual data best. The results demonstrate that the four latent variables involved in the study have good discriminative validity.

Exploratory factor analysis (EFA). Using Principal component analysis and carry on direct rotation with maximum variation. $\mathrm{KMO}=0.879$, the significance of Bartlett's spherical test is 0.000 , indicating that the data are suitable for exploratory factor analysis. Analysis result extracts 4 factors whose eigenvalues over $1,72.199 \%$ of the total variation of the scale item was explained. The rotational component matrix shows that factor 1 is severity, factor 2 is legality, factor 3 is risk; factor 4 is controllability. These are in accordance with the theoretical hypothesis.

Correlation analysis. The results are as follows, risk, severity, legitimacy of tourism product harm crisis has a significant negative impact on tourists' travel intention respectively. There is no significant correlation between controllability and travel intention,

Regression analysis. Using SPSS 23.0 to carry out multiple regression analysis. The results of regression analysis show that: (1) adjusted $\mathrm{R}^{2}$ is 0.559 , tolerance of four factors is TOL $>0.10$, and VIF $<10$, show that there is no significant collinearity among variables; (2) The risk has a significant negative impact on travel intention, the impact of severity on travel intention isn't significant, legitimacy has a significant negative impact on travel intention, controllability has a significant negative impact on travel intention.

Table 1 Multiple regression analysis summary table

\begin{tabular}{|c|c|c|c|c|c|c|}
\hline \multirow[t]{2}{*}{ Model } & \multicolumn{2}{|c|}{ Unstandardized coefficient } & \multirow{2}{*}{$\begin{array}{c}\text { Standardized } \\
\text { coefficients } \\
\text { beta }\end{array}$} & \multirow[b]{2}{*}{$\mathrm{t}$} & \multicolumn{2}{|c|}{ Collinearity diagnosis } \\
\hline & B & $\begin{array}{l}\text { Std. } \\
\text { Error }\end{array}$ & & & Tolerance & VIF \\
\hline Constant & 9.218 & .603 & & $15.274^{\text {***⿲二丨匕 }}$ & & \\
\hline Risk & -.247 & .077 & -.158 & $-3.223^{*}$ & .719 & 1.391 \\
\hline Severity & -.026 & .04 & -.031 & -.634 & .703 & 1.422 \\
\hline Legitimacy & -.773 & .045 & -.735 & $-17.236^{* * *}$ & .955 & 1.047 \\
\hline Controllability & .113 & .047 & .107 & $2.425^{*}$ & .886 & 1.128 \\
\hline
\end{tabular}

$\mathrm{R}^{2}=0.566 ;$ Adjusted $\mathrm{R}^{2}=0.559 ; \mathrm{F}=81.544$

Note : $\mathrm{P}<0.05, \stackrel{\text { *** }}{\mathrm{P}<0.001}$ 
Discussion. This paper discusses the impact of tourism product harm crisis attributes on travel intention, draws the following conclusions through data analysis.

Risk has a significant negative impact on travel intention. The greater the perceived risk, the lower the willingness to travel; conversely, the higher the willingness to travel.

Severity has no significant impact on travel intention. After interviews, most of the respondents recognized that the incident is very serious for the injured, the sense of severity is not very strong for themselves and will not affect travel intention. Only when people experience crisis events, can they feel the severity of the crisis. Because respondents' perception of severity is more real and physiological feeling is the strongest in a real crisis situation.

Legitimacy has a significant negative impact on travel intention. In this paper, the legitimacy of crisis reflects the level of customer-company identification and the organization conforms to laws and regulations. In certain range of acceptance, the higher the level of customer-company identification, the stronger the ability to resist the negative information about the company. When customer perceived negative information beyond a certain range, the higher the level of customer-company identification, the stronger the response of the customer to the negative information of the company, maybe boycotting the product of the company and spreading negative word of mouth[29].

Thus, when customers perceived low severity within the range of customers' acceptance, the higher the level of customer-company identification, the higher the customers perceived legitimacy, the higher the travel intention is. The reasons for the result may be as follows. According to the data, the perceived severity of respondents is generally high, when customers perceive high severity beyond the range of customers' acceptance, the higher the level of customer-company identification, the higher customers perceived legitimacy, the lower the travel intention is. As a result, legitimacy has a negative impact on travel intention.

Controllability has a significant positive impact on travel intention. After interviewing with 30 respondents, it was found that the more crisis events can be controlled, the safer the zoo is. The tourists felt that the possibility of the crisis would be reduced under the premise of the zoo's regulations. As a result, the higher the controllability, the stronger the willingness to travel.

Implication. The paper enriches the theory of product injury crisis management system.Because of the rapid media dissemination, tourism product harm crises have aroused widespread concern in the society. The occurrence of crises have caused a bad influence on the brand image of the destination, and decrease the travel intention of the tourists. The enterprise know the attributes of tourism product harm crisis through this paper and put forward specific solutions to prevent these problems.

Limitations. Limitation of sample. The respondents are mainly concentrated at the age of 18-25 in Sichuan province. This is not enough to represent all ages and areas. Future studies will increase samples of different ages and areas.

Limitation of attributes. It's not completely to explore tourism product harm crisis with four attributes. Future research can explore whether the product injury crisis has other attributes. With further research in the future, more attribute dimensions can be added to enrich the attribute of injury risk in tourism products.

Limitation of crisis restoration strategies. Because of the authors' limited ability, the paper does not involve the study of crisis restoration strategies. Future research can be aimed at different tourist product harm crises attributes to establish restoration strategies and apply theory to practice.

\section{Summary}

In this paper, tourism product harm crisis attributes consist of four attributes, including risk, severity, legitimacy and controllability. The scale has good reliability and validity and fit the model well. At the same time, this paper also studied the relationship between four attributes and travel intentions. It helps to solve the problem of product harm crisis, such as reconstruct and strengthen destination image in order to minimize negative impact on destination. 


\section{Acknowledgements}

Supported by Young Tourism Expert Training Program of Sichuan Provincial Tourism Development Committee (SCTYETP to Yue Li); by Scientific Research Foundation for Returned Scholars, Sichuan Provincial Human Resources and Social Security Department (to Yue Li); by Soft Science Project of Science \& Technology Department of Sichuan Province (to Yue Li).

\section{References}

[1] Siomkos G J, Kurzbard G: European Journal of Marketing, Vol. 28 (1991) No.2, p.30.

[2] COOMBS W T, HOLLADAY S J: Management Communication Quarterly, Vol. 16 (2002) No.2, p.165.

[3] Y. Yang, W. Li, S. Li: China Management Studies, Vol. 6 (2011) No.3, p.90. (In Chinese)

[4] Z. Fang: Productivity Research, Vol. 22 (2007) No.4, p.63. (In Chinese)

[5] Z. Fang, M.H Jiang, Y. Yang: Management World, Vol. 26 (2010) No.12, p.105. (In Chinese)

[6] COOMBS W T: Journal of Public Relations Research, Vol. 10 (1998) No.3, p.177.

[7] LEI J, DAWARN, G RHAN-CANLI Z: Journal of Marketing Research, Vol. 49 (2012) No.3, p.336.

[8] Beirman D: CAUTHE 2003: Riding the Wave of Tourism and Hospitality Research, (2003) p.1146.

[9] Rittichainuwat B N, Qu H, Mongkhonvanit C: Journal of Vacation Marketing, Vol. 14 (2008) No.14, p.5.

[10]Irvine W, Anderson A R: Tourism, security \& safety: From theory to practice, (2006) p.169.

[11] Hall C M, Timothy D J, Duval D T: Journal of Travel \& Tourism Marketing, (2003) No.15, p.2.

[12]Mansfeld Y: Tourism, security \& safety: From theory to practice, (2006), p.271.

[13]Laufer D, Silvera D H, Meyer T, et al: Academy of Marketing Science Review, Vol. 2005 (2005) No.1.

[14]D.D Cui, X.G Zhang: Journal of Zhongnan University of Economics and Law, Vol. 55 (2012) No.2, p.50. (In Chinese)

[15]K. Jiang: A Study on Tourist city image and Tourists 'Behaviors under unconventional emergency, (Ph.D., University of Electronic Science and Technology of China, China 2010), p.9 (In Chinese)

[16]M. Tu, F.J Jing, X.D, Wang: Journal of Business Economics, Vol. 24 (2004) No.11, p.31. (In Chinese)

[17]Y.M Lu: Science of Social Psychology, Vol. 28 (2012) No.3, p.27. (In Chinese)

[18] X. Dai: Journal of Beijing Institute of Technology (Social Sciences Edition), Vol. 12 (2010) No.6, p.96. (In Chinese)

[19]Suchman M. C: Academy of Management Review, Vol. 20 (1995) No.3, p.571.

[20] Y.P Li, S.T Wu, T. Yang: Journal of Wuhan University of Technology (Social Sciences Edition), Vol. 25 (2012) No.3, p.415. (In Chinese)

[21]L.L Ma: Management World, Vol. 27 (2011) No.5, p.120. (In Chinese)

[22]X.D Wang, F.J Jing, M. Tu: Management Review, Vol. 25 (2013) No.9, p.148. (In Chinese)

[23]Bernard Weiner: Review of Educational Research, Vol. 42 (1972) No.2, p.203.

[24]Blodgett J G, Wakefield K L, Barnes JH: Journal of Service Marketing, Vol. 9 (1995) No.4, p.31.

[25]Fred Van Raaij W, Pruyn A T H: Psychology \& Marketing, Vol. 15 (1998) No.8, p.811.

[26]Wen-Hsien Huang: International Journal of Service Industry Management, Vol. 19 (2008) No.4, p.521.

[27]Y.C Yue, X.H Xu: Chinese Journal of Management, Vol. 8 (2011) No.8, p.1213. (In Chinese)

[28] Fornell C, Larcker D F: Journal of marketing research, Vol. 18 (1981) No.1, p.39.

[29]Bhattacharya C B, Sen S: Journal of Marketing, 67（2003） No.2, p.76. 